\title{
Del ser en tanto que ser manierista. (La Maniera según las dos acepciones derivadas de los textos y el arte italiano del siglo XVI)
}

RESUMEN. El manierismo surgió de la necesidad personal de los grandes artistas florentinos, sobre todos, Leonardo, Miguel Ángel y Rafael, que buscaron modos propios de expresión, manieras, con las que superaron los preceptos en los que se habían formado a finales del siglo XV y principios del XVI. El origen de la Maniera estuvo, pues, ligado a las libertades técnicas, estilísticas y expresivas, de cada artista, esto es, a la manifestación de personalidades únicas e intransferibles. Los seguidores de estos creadores sistematizaron las cualidades de los maestros y, con el apoyo de un nivel teórico tendente a establecer las pautas de la representación, generaron un efecto contrario, el de los seguidores de la maniera elegida. De ese modo, renunciaron a los principios implícitos en la acepción original del término.

Palabras clave: Renacimiento, Manierismo, Teoría, Boticelli, Leonardo, Miguel Ángel, Rafael, Vasari, Parmiginiano, Tiziano.

ABSTRACT. The origin of Manner comes from creative artists, innovative personalities, and extraordinary men. The production of works of art was unique. The disciples were theoretical men; they've invested the general terms. They went on working as their master and turned into conservatives' artists.

Key words: Renaissance, Mannerism, Theory, Boticelli, Leonardo, Miguel Ángel, Rafael, Vasari, Parmiginiano, Tiziano.

Es claro que si un ser es lo que es o puede ser, el ser manierista, que cuenta con aval universitario, es, sobre toda polémica historiográfica, lo que es o puede ser el manierismo. No otra cosa que una tendencia definida que alternó con otras tales y como ella producto de un desarrollo histórico y social en el que significó y sin el que no podemos aprehender su verdadero ser. Tal es el objetivo del ensayo que, planteado así, en la certeza de su existencia autónoma pero dependiente de la supraestructura del Quinientos, ha de valorar el ser en sí y en sus relaciones. Desde Heidegger, que aunó el análisis fenomenológico de Husley y la contextualización en la que lo proyectó Dilthey, no puede ser de otro modo.
Hablar de manierismo sin tener en cuenta que sólo fue una parte de la supraestructura o generalizarla sin precisar la naturaleza de sus componentes son graves errores metodológicos que debemos desechar. El manierismo no constituyó una etapa, formó parte de ella junto a la pervivencia agónica del Renacimiento clásico y la génesis protobarroca auspiciada por el distinto sentir en la misma coyuntura ${ }^{1}$. Los parece-

\footnotetext{
${ }^{1}$ H. WÖLFfLIN: Conceptos fundamentales de la Historia del Arte, Espasa Calpe, Madrid, 1924. Cito por la reedición de 1997, Págs. 25 y sigs. Reconoció la diversidad de los estilos en el premanierismo florentino de Boticelli y de Lorenzo di Gredi. Tales correspondieron
} 
res fueron miscibles y los artistas fluctuaron en función de las necesidades personales y las categorías y las posibilidades reales de cada cual en su medio.

Los grandes artistas del Quinientos no sintieron el manierismo como movimiento o estilo colectivo sino como interpretación personal del organicismo que preexistía, y, en tal sentido, no se sentían manieristas ni protobarrocos - los barrocos tampoco tuvieron conciencia de tal -; sí herederos de la tradición renacentista con la que, empero, no se alinearon, sino sobre la que procedieron y a la que, con nuevos fundamentos intelectivos, transformaron en su desarrollo formal. Tal superación no procedió de la madurez de una nueva estructura mental, sino de la proyección lineal de la preexistente sometida a las tensiones, las dudas y las contradicciones de un momento coyuntural.

La transformación manierista surgió de la transgresión de las fórmulas del Renacimiento cuyo lenguaje formal, libre de reglas, aceptó. Y al hacerlo formó parte de éste. Se opuso, tal propuso Fiedlanter, pero como negación interior y no como oposición de contrarios. Por ello, Wölfflin ${ }^{2}$ lo consideró una desviación en la evolución del Renacimiento, que podemos considerar epígono, como afirmó Previtali; pero sólo en la parte que le correspondió en el supraser que lo albergaba y realmente lo constituía. En función de éste, como parte activa del mismo, hemos de plantear el estudio del ser que inició Dvorak en la órbita visibilista. Mas pocas veces el proceso cognoscitivo es tan complejo y los juicios de valor condicionados por los imperativos categóricos de los métodos lo acotan a la vez que nos alejan de su verdadero ser. No se puede

\footnotetext{
a conceptos distintos e igualmente característicos de una misma etapa.

${ }^{2}$ H. WÖLFFLIN: Conceptos fundamentales de la Historia del Arte, Op. Cit. Págs. 38 y sigs.
}

obviar la unicidad del arte. La obra de arte no concluye con el acabado del autor, con la configuración que él determina, sino cuando produce la transformación del espectador al que va dirigida mediante contenidos concretos. Aproximarnos a tal relación es nuestro deber.

Para ello, hemos de dilucidar cuándo y cómo se pasó del saber práctico fruto del proceso perceptual controlado con rigor protocientífico en relación con la invenzione que dio forma simbólica a las referencias literarias mediante las imágenes de la Antigüedad sobre la que procedió y a la que pretendió superar, ya esencializada y depurada en belleza, ya supeditada a la cruda realidad, al conocimiento sensible a través de la percepción visual del concetto subjetivo. Lo podemos apreciar en Miguel Ángel. En su obra y, tal demostró Panofsky ${ }^{3}$, en su terminología; pues, en la etapa florentina vinculada al esencialismo neoplatónico nos habló de idea y cuando lo superó con criterios subjetivos lo hizo de concetto. No es un simple juego de palabras, sino una inversión conceptual que se manifiesta a través de ellas. Tal enraíza en el pensamiento cuatrocentista.

El humanismo, en sus escalas místicas tendentes a la aprehensión del máximo relativo que lo aproxime al mínimo absoluto constituido por el ser supremo, Dios, planteó la belleza en tanto que tal ${ }^{4}$. La categoría esencialista en estado abstracto prevaleció, y, de ese modo, Ficino mantuvo que el juicio o imagen mental del artista, su idea o esencia aprehendida, supera siempre a la imagen virtual que reproduce; pero, reproducida, la belleza radica en el resultado plástico de la obra de arte y no en cuanto de

\footnotetext{
${ }^{3}$ E. PANOFSKY, Ideas y conceptos en la Teoría del Arte, Cátedra, Madrid, 1992, Págs. 115 a 121.

${ }^{4}$ N.Q. RoBB: Neoplatonism of the italian renaissance, Londres, 1935. Es una lectura fundamental sobre el desarrollo neoplatónico en el pensamiento humanista.
} 
material tiene el objeto o la persona dada. Es decir, en la esencia artística. De ahí que determinados artistas, si la belleza radica en el origen incorpóreo de los objetos, en la idea que los define, renunciasen a plasmar su imagen, ya que tal acto no la iguala ${ }^{5}$. Y si no lo hace, era preferible una versión mental y subjetiva, concetto, que evitara las comparaciones y le permitiera realizarse en función de la esencia artística. Tal operación era la maniera o estilo personal que se desarrollaba a partir de los modelos heredados. Por lo tanto, tener maniera era poseer un modo personal.

La maniera era más acusada cuanto mayores eran las dotes y la personalidad del artista que la pretendía, y ello, la creatividad de tales artistas; por ejemplo, de Miguel Ángel, Tiziano o Philibert de L'Orme, por citar autores en distintas disciplinas y contextos, constituyó el acto pleno manierista. A través de éste hay que estudiar el fenómeno; pero antes es preciso constatar el noumeno del que partió y que constituyó una fase previa en la que se detectan rasgos subjetivos pero supeditados a las normas vigentes. Tal sucedió en Florencia a finales del Cuatrocientos. Boticelli convirtió el fino movimiento de Fra Filippo Lippi en esquema sistemático con el que configuró la silueta curvilínea de sus personajes de modo un tanto convencional ${ }^{6}$. La estilización preconizó la línea serpentinata. Lo mismo se puede decir del juego de curvas y contra curvas derivado de la compensación de volúmenes en el espacio de los grupos de Pollaiuolo; y del Entierro de Cristo, de Miguel Ángel, en 1507; y del Incendio del Borgho, de Rafael, ya en 1515. No obstante,

\footnotetext{
${ }^{5}$ Platón, Fedro, 250 B. Propuso la realidad empírica como imagen de la idea que, en cuanto imagen, participa poco de ella.

${ }^{6}$ H. WÖLFfLIN, Conceptos fundamentales de la Historia del Arte; Op. Cit. Págs. 259 y 260. Aseguró que las asimetrías proporcionan las formas de movimiento vital.
}

aceptaron la relación entre los elementos y la subordinación al espacio único y a los fondos sujetos a las leyes de la geometría. Buscaron y consiguieron su maniera; mas tal compromiso los ligó y por ello sólo constituyeron un antecedente categórico o premaniera florentina.

Visto así, la teoría del arte manierista a la que tratamos de aproximarnos no se fundamentó en la maniera en tanto que maniera, sino en ella en función de los nuevos conceptos intelectivos que se proyectaron en circunstancias históricas concretas; esto es, en el valor expresivo sobre el medio en el que operó, fuese la vida cortesana o la curia pontifical, y la situación caótica a la que condujeron la inestabilidad política y las reformas religiosas. Repárese en que las nuevas tendencias filosóficas no constituyeron la estructura ${ }^{7}$ del pensamiento del Renacimiento Tardío, sólo fueron niveles que la transitaron y produjeron transformaciones importantes pero relativas. Podemos ver la pervivencia del esencialismo neoplatónico en la Gesamtkunswerk o principio de armonía entre la arquitectura, la escultura o pintura y la decoración; que se dio en las Logias vaticanas de Rafael y, por citar ejemplos familiares, en la escultura funeraria de los talleres ligures de Doménico Fancelli de Settignano y Antón María Aprile de Carona. También en Durero, que, aun preocupado por cuestiones inmanistas y el problema de la edad del hombre y la muerte, tan atento estuvo a la geometría. Y, lo que es más importante, cuando parecía olvidado por Miguel Ángel, reapareció en la Cúpula de San Pedro, auténtica culminación del Renacimiento Pleno.

En definitiva, el Manierismo en acto fue fruto de la agonía íntima de los grandes creadores y de la expresión de ello cuando

\footnotetext{
${ }^{7}$ Ellas conviven con otros niveles de pensamiento que proceden del Renacimiento Pleno.
} 
derogaron las normas procientíficas y el esencialismo neoplatónico. Ello siempre que desarrollasen sus inquietudes expresivas sobre los modelos Cuatrocentistas ${ }^{8}$; pues, en caso contrario, hablaríamos de expresionismo protobarroco. La inseguridad ante los acontecimientos y la consiguiente transformación de los caracteres y las intenciones son quienes determinaron los distintos niveles que originaron las contradicciones artísticas.

A Barash ${ }^{9}$ le preocupó, sobre todo, junto a la irregularidad teórica y los cambios sociales sobre los que hablamos, establecer fundamentos y elementos comunes entre la subjetividad individualista de los grandes creadores y las distintas escuelas supranacionales. Se pueden detectar en el marco de la pura visualidad; pero siempre que tengamos en cuenta que el principal concepto, el de fantasía irracional, se proyectó tanto en los fundamentos literarios que generaron las imágenes y en los símbolos que las representaron y se han de estudiar desde un punto de vista teórico y en contacto con las fuentes, como en el plano plástico. Ello fue fruto del convencimiento de que no todo es materialmente racional y tal y lo subjetivo no soportan una medición precisa.

El manierismo no admitió que la única interpretación correcta fuese la sometida a las normas geométricas y anatómicas. Surgió, de modo ineluctable, un nuevo concepto que explicó Vasari ${ }^{10}$, el disegno. Detengámonos en aclarar en qué consiste, pues se suele confundir con el dibujo y no

-

${ }^{8}$ M. DWORAK, «Über Greco y den Manierismus»; en Kunstgesch al Geitsesgesch, pág. 271. Intentó hallar la relación entre la subjetividad manierista y el naturalismo al que llegó el Renacimiento Pleno.

${ }^{9}$ M. BARASH, Teorías del Arte. De Platón a Winckelmann; Alianza Forma, Madrid, 1991 (Nueva York, 1985), Págs. 167 y sigs.

${ }^{10}$ VASARI: Vidas, I, Pág. 168. es lo mismo. Diseño es un plan subjetivo que se materializa mediante el dibujo; mas no tal en propiedad. El dibujo, en sí, se basa en la línea y ella no existe en la realidad, es la trampa con que la presuponemos y si no lo hacemos depende de nuestro concetto y el disegno o plan que lo materializa. Por ello, el disegno manierista es reconocible tanto en el arte florentino y romano que se fundamentó en el dibujo y el volumen, como en el veneciano cuya configuración procedió a través del color y la luz. En ambos casos, concetto y disegno, es decir, la imagen personal y el plan que la elaboró, fueron la pura subjetividad que determinó códigos fantásticos en los que incluyó o no elementos tales. Tal expuso Hauser ${ }^{11}$, la consecuencia fue la negación de la armonía clásica al romper la unidad espacial con escenas desdobladas en las que cada parte se rige por principios autónomos; operación en la que no tiene porque haber equivalencias en escalas, distribuciones de espacio, temas y movimientos, y permite la inclusión de ellos en espacios tradicionales. Pero el alcance fue mayor y concetto y disegno también buscaron en la gracia, tal apreció Pico della Mirandola ${ }^{12}$, una cualidad creativa que no está en los objetos dados y es cognoscible mediante el dibujo o la configuración equivalente. Ella era patrimonio del manieroso: del artista exquisito, refinado. Sin duda, la maniera de los grandes creadores, como Rafael y Miguel Ángel y Tiziano, se puede identificar con el arte-creación que propuso Ramón Gaya ${ }^{13}$.

\footnotetext{
${ }^{11}$ A. HAUSER: Historia social de la Literatura y el Arte, Guadarrama, Barcelona, 1980, Pág. 13.

${ }^{12}$ P. DE LA MirándOla, Commento alla Canzone di Girolamo Beniviene, Garín, Florencia, 1937 y 1942, Vol. I, Págs. 451 a 458.

${ }^{13}$ R. GAyA, Velázquez, Pájaro solitario, Biblioteca de la Cultura Andaluza, Granada, 1984, Págs. 35 a 39.
} 
Veámoslo con los ejemplos. Primero con Miguel Ángel. Sí, aunque Panofsky ${ }^{14}$ no lo considerase manierista; y no le faltó razón en la acepción generalizada con la que concluiremos, pero ella es distinta de la individual a la que remitimos. Miguel Ángel sí tuvo maniera, y concetto y disegno y gracia. Otra cosa es que no fuese un amanierato convencionalista. Por lo tanto, fue manierista en el parecer que defiendo. Es fácil demostrarlo. Basta con el vestíbulo y la sala de lectura de la Biblioteca Laurenciana ${ }^{15}$, en 1523-25, espacios autónomos que conviven y muestran diferentes coeficientes de espacilidad: el vestíbulo en tanto recinto fantástico que, en su irracionalidad, envuelve a la escalera por la que se accede a la sala de lectura; ella diáfana y acorde a su función prístina. El ingenio sustituyó al esquema armónico de los módulos geométricos; tal la composición piramidal de la primera Piedad, en 1497, es transida por la línea serpentinata de la del Duomo de Florencia, en 155055, que triunfa libre en el impulso ascensional de las de Palestrina, cerca de 1555, y Rondanini $^{16}$, en 1552 a 1564 . Ése espacio fantástico que es el vestíbulo, contiene, a la vez, elementos tales. Caso de las ventanas ciegas y sus correcciones ópticas y de las columnas voladas y empotradas en el muro, que, desposeídas de función tectónica, carecen de otro sentido que el específico decorativo. Su imagen es clásica pero no su naturaleza debida al disegno. Éste determinó el nuevo orden gigante que, ignorando las leyes de la geometría tectónica, unificó los pisos del Palacio del Senado, en 1538, y configuró el alzado de la Capilla Sforza.

Ya lo había hecho Rafael con las pilastras de la fachada del jardín de Villa Ma-

-

${ }^{14}$ E. PANOFSKY, Estudios de Iconología, Alianza Forma, Madrid, 1972, Pág. 241.

${ }^{15}$ L. MurriA, Miguel Ángel, Ediciones Destino, Barcelona, 1992 (Londres, 199º), Pág. 125.

${ }^{16}$ L. Murria, Miguel Ángel; Op. Cit. Pág. 200. damme, pero ellas tienen un valor plástico atectónico y premanierista. Son componentes fantásticos cuya verdadera dimensión luce junto al purismo de los proyectos de Bramante y de la cúpula de la Iglesia de San Pedro con la que él mismo trascendió el modelo de Brunelleschi, al que, incluso, acercó al Pantheon de Agripa. Y también junto al expresionismo protobarroco de los capiteles y las cornisas de la Capilla Sforza, que, en cierta medida, equivale al movimiento realizado que Freud ${ }^{17}$ detectó en el Moisés y se puede aplicar a las pinturas del Génesis en la bóveda de la Capilla Sixtina.

Al lado de ellos, quizás, los elementos manieristas desfiguradores del espacio de mayor repercusión sean el pavimento de la Plaza del Capitolio; la circulación ascencional e inversa del Juicio Final de la Capilla Sixtina; y el altar en esviaje de la Basílica de Santa María de los Ángeles ${ }^{18}$. Equivalen, en sí, a la desfiguración formal que vemos en las esculturas de la capilla medicea, en Florencia, en el alargamiento desproporcionado de la sala de lectura de la Biblioteca Laurenciana y en las pinturas de la Capilla Paulina.

El Palacio del Té en Mantua, proyectado por Giulio Romano, en 1525, es todo un manual de nuestra definición de manierismo. Son múltiples los aspectos a señalar. La independencia espacial y la organización independiente de cada espacio se pueden observar, trasladadas al plano, en las fachadas con distintos diseños y sin régimen de equivalencias y en la sucesión de estructuras que las configuran. Lo irracional en los fustes rústicos del vestíbulo que, empero, sostienen una bóveda de traza refinada con casetones octogonales inspira-

\footnotetext{
${ }^{17}$ S. FREUD, Psicoanálisis del Arte, Alianza, Madrid, 1970, Págs. 88 y sigs.

${ }^{18}$ C. DE TOLNAY, Miguel Ángel. Pintor, escultor y arquitecto, Alianza Forma, Madrid, 1985, Págs. 86 y sigs. Analizó la última etapa de Miguel Ángel.
} 
dos en la Basílica Majencio ${ }^{19}$; y la fantasía delirante en el inacabado de los huecos de la fachada y los trampantojos pintados sobre el cuerpo de ventanas del patio de honor. Es el ilusionismo que trasladó a la arquitectura volada y salomónica que parece aplastar el cuerpo rústico sobre el que alza en la sala estival del Palacio Ducal. Lo hemos visto en Miguel Ángel y ahora en Giulio Romano y, con distinto desarrollo, lo podemos ver en los vanos venecianos y la escenografía de Serlio y Palladio $^{20}$. Es un Arte-Creación que también se dio en las sorprendentes fusiones de masas de la escultura de Alonso Berrugete y en la multiplicación y comunicación de espacios mediante espejos y los tonos dorados de la pintura de Veronés y Tintoretto.

Hasta ahora hemos hablado de tener una maniera personal, es decir, de una propuesta individual e intransferible propia de grandes creadores. De un ser manierista en tanto individualidad que reaccionó y se manifestó en un momento concreto. Pero hay, como dijimos, otra acepción. Se refiere no a tener una maniera sino a seguirla. En tal caso, no hablamos de fundamentos personales, del acto creativo, sino de la adopción de normas convencionales sobre las que se expresaron las inquietudes de cada cual. Téngase muy en cuenta porque se suele confundir y con ello se tergiversa el ser. El artista siguió unas reglas como antes habían hecho los cuatrocentistas; reglas que no tomaron de las ciencias sino de las manieras de los grandes creadores con los que no pudieron competir en creatividad.

Su definición tuvo dos grandes necesidades: transmitir los conocimientos de

\footnotetext{
${ }^{19}$ L.H. HeYDENREICH y W. LOTZ, Arquitectura en Italia, 1400-1600, Cátedra, Madrid, 1992, pág. 362.

${ }^{20}$ M. Wundram y T. PAPE, Palladio, Benedikt Taschen, Berlín, 1990, pág. 87. Palladio proyectó el Pórtico del Palacio Chiericati con tal sentido ilusorio que sirve de stoa a la Plaza d'Isola.
}

taller e intercambiar opiniones con los receptores para fijar los conceptos; y ello fue la causa del desarrollo de los tratados y la intención de la teoría del arte. De ésta surgieron los complejos programas iconográficos que generaron la vertiente decorativista. Ya no es el Arte-Creación, es el ArteArtístico de Ramón Gaya ${ }^{21}$. Forma parte del ser manierista, pero no es por sí mismo, el manierismo. Es una de las dos acepciones del mismo ser que, de ningún modo, es inteligible sin la anterior; pero tiene una identidad definida y ligada al proceso que, tras el Sacco de Roma y la restitución de las relaciones entre el Emperador y el Papa, condujo, ora a la cristianización contra reformista; ora a la recontextualización en el origen cortesano del premanierismo florentino. Hay quienes, tal Pinder ${ }^{22}$, vieron en ello la plenitud del manierismo y le otorgaron carácter transitorio; que tiene en arte si confundimos la proyección de las escuelas regionales con el ser, no si apreciamos el desarrollo de esta acepción en tanto que tal.

Parmiginiano es un buen exponente con su Madonna del Collo Lungo, en 1535. La Virgen ocupa un primer espacio y desarrolla el canon de, al menos, diez cabezas, que Cesariano dedujo de Vitruvius y ya habían utilizado Pontormo, en la Madonna con santos de San Michele Visdomini, en 1518, y Rosso, en el Cristo sostenido por los ángeles de Boston, en 1525-26. Tal es un carácter extensible a cuantos siguieron la maniera. Como Benvenuto Cellini, en la Diana de Annet, y Leone Leoni, en el grupo de Carlos $V$ venciendo al Furor, en 1549-55. Los ejemplos

\footnotetext{
${ }^{21}$ R. GAYA, Velázquez, Pájaro solitario; Op. Cit. págs. 35 y sigs.

${ }^{22}$ W. PINDER, Zur Physiognomik des Manierismus, Die Wissenschaft aun Scheidewege, Ludwig Klagespestschrift, 1932, pág. 149. R. GAYA, Velázquez, Pájaro solitario; Op. Cit. págs. 35 y sigs.

${ }^{22}$ W. PINDER, Zur Physiognomik des Manierismus, Die Wissenschaft aun Scheidewege, Ludwig Klagespestschrift, 1932, Pág. 149.
} 
serían interminables y sobre ellos destacan dos que lo acentúan, Perino del Vaga y El Greco; no obstante, elegí como paradigma la obra de Parmiginiano porque presenta un segundo espacio, independiente, con su organización y un personaje en otro escala. Son dos mundos distintos que enlazó mediante el ilusionismo de la sucesión lineal de las columnas del plano inferior que, en su desarrollo en altura, se convierten en el fuste único y la sombra que le corresponde del primer plano. En cuanto concepto estuvo asaz próximo a la arquitectura de Giulio Romano; mas no aportó, como éste, novedades estilísticas personales. No tuvo $m a-$ niera propia, siguió una maniera teórica.

En ello coincidieron los autores citados. La singularidad de cada uno estuvo en la relación de los componentes fantásticos con los convencionalismos a los que se debieron. Pontormo fue singular por la caprichosa irrealidad de su paleta, en la Deposición de Cristo, en 1526-28; Pedro Machuca y Bronzino por sus movimientos exagerados y rígidos; y El Greco, el más singular de todos, por su pincelada suelta y vívida pero sujeta a los límites de contorno que marcan el dibujo ${ }^{23}$.

Los teóricos que siguieron una o varias manieras definieron el desarrollo de las escuelas sobre las que, según los condicionantes geográficos, incidieron las aportaciones de los grandes maestros.

Previtali reconoció que en ellos estuvo el cambio con respecto a la tradición y que los manieristas, es decir, los seguidores de la maniera o escuelas, les siguieron y lo confirmaron. Matizó el factor creativo que media; pero no llegó a proponer el Manie-

\footnotetext{
${ }^{23}$ A. LuQUe TERUEL: Adminículo a la comprensión de Velázquez, Caja de Ahorros San Fernando, Sevilla, 1998, Pág. 90. La pincelada ágil y suelta de El Greco transita de modo novedoso el espacio al que se circunscribe, delimitado por el dibujo.
}

rismo como creatividad subjetiva ${ }^{24}$ sino en cuanto teorización y adopción convencional de tal. Aquí planteo el ser en potencia y en acto, y éste, en la mentalidad cincuecentista, acaeció primero en los que crearon su maniera. Cuando Longhi afirmó que Berrugete fue un adelantado de la manera, quiso decir que no la seguía porque tenía la suya, ya hacia 1515.

El valor del estilo se impuso al protocientífico y la maniera, esto es, el ser manierista, fue forma teorizable y expresión personal. Vasari o Ammannati pudieron reducir a esquemas convencionales la configuración de Miguel Ángel ${ }^{25}$, pero no pudieron captar un ápice de su arrebatado pathos, y no porque fuese un caso extremo y proexpresionista; tampoco Vázquez, El Viejo, pudo reflejar, en la Piedad de Ávila, el bello ethos de la del Vaticano.

Por ello, propongo que los grandes creadores constituyeron el acto del Manierismo Pleno, mas éste, en tanto forma teorizable pese a la expresión subjetiva que conllevó, aportó, en la evolución lineal supeditada al devenir histórico, los conceptos que permitieron, mediante el crédito de estilo generado por la erudición teórica, mantener las manieras $\mathrm{y}$, de algún modo, ampliarlas. Así, seguir las manieras fue asegurar un estilo y ello constituyó un segundo momento o acepción del Manierismo Pleno. Son conceptos distintos, lo que ocurre es que, siéndolos, tuvieron una clara relación de procedencia y produjeron una transformación parangonable, pese a las distancias, del espectador. Tal originó la evolución del Manierismo Tardío que, tras los movimientos producidos por el Sacco, constituyó la autarquía del arte italiano en Europa.

\footnotetext{
${ }^{24}$ Distinta a otra forma de crear que, por seguir directrices premeditadas, es sólo producción.

${ }^{25}$ E. PANOFSKY, Estudios de Iconología, Op. Cit. Pág. 241.
} 
En ello radica la importancia de señalar la raíz primigenia de las tres grandes escuelas. Las teorías venecianas de Colon$\mathrm{na}^{26}$, Pino ${ }^{27}$, Doce $^{28}$ y Sorte ${ }^{29}$, asumieron las directrices del pensamiento florentino ${ }^{30}$, mas giraron en derredor de las aportaciones específicas artísticas del Veneto; es decir, de la pincelada, el toque, los medios tonos y la luz de Tiziano, Tintoretto y Veronés. Miguel Ángel fue la gran referencia de la escuela florentina, con su obra y con las reflexiones teóricas que difundió a través de Ascanio Condivi ${ }^{31}$ y que tuvo en cuenta Vasari. La lista de afiliados es interminable: Pontormo, Bronzino, Vasari, Ammannati, Parmiginiano, la escuela de Fointenebleau, Bartolomé Ordóñez, Vázquez El Viejo. En Roma, las necesidades trentinas fueron las fuerzas que titilaron y aunaron las referencias de Miguel Ángel y Rafael en pos de un arte heroico, que practicaron autores como Piombo, Volterra, Pedro Machuca y Gaspar de Becerra, cuyo eco llegó a Diego de Pesquera y Jerónimo Hernández. Fueron directrices miscibles entre sí y con las otras alternativas del momento. Su difusión dependió de las realidades políticas y de la posición de los Estados ante las reformas religiosas.

Volvamos, pues, al teoricismo responsable de la narrativa y el simbolismo literario que actuó como simiente de la segunda acepción del ser que constituye el Manierismo Tardío. Tal teoricismo fue, desde el principio, causa de la ontología virtuosista y de la aplicación práctica de la experien-

${ }^{26}$ F. COLONNA, Hypenerotomachia Poliphili.

${ }^{27}$ P. PINO, Dialogo della Pintura (1548).

${ }^{28}$ L. DOLCE, Dialogo della Pintura, intitolato s`Aretino (1557).

${ }^{29}$ C. SORTE, Osservazione della Pintura.

${ }^{30}$ A. Blunt, Artistic Theory; Op. Cit. págs. 39 y sigs. Estudió los tratados de Coloma, Pino, Dolce y Sorte.

${ }^{31}$ A. CONDIVI, Life of Michelangelo; Círculo Bibliófilo, 1981 . cia sensorial. También del abuso que degeneró en la confusión de lo refinado con el trazo rebuscado y forzado ${ }^{32}$, sendero sin salida sobre el que triunfó la recuperación de las formas naturales del primer barroco. Ello produjo variantes que, aun relacionables con las escuelas, tuvieron identidad suficiente para considerarlas individualmente. Distingamos entre decorativismo sensorial y decoración como identidad.

Al hablar de decorativismo sensorial lo hago en función de tales aplicaciones en una obra plástica definida y no como proyecto decorativo. E. Schön, en el grabado $E l$ Diablo gaitero, en 1535, concibió la figura mediante la agrupación de distintos organicismos que, en su unicidad, no guardan relación con la que configuran. Ello es posible por la forma de organización de los objetivos o Ley de la Buena Forma. Tal es el punto de partida de un nuevo acto creativo que culminó con Arhcimboldo en la Alegoría de la Primavera, en 1565. La unión de formas origina la configuración fantástica, pero cada forma, como unidad, conserva su configuración propia. Las partes no equivalen al todo y pueden formar parte de uno o varios todos. No obstante, no se puede hablar de manieras personales, pues no proceden de la subjetividad sino de ella aplicada a leyes universales determinadas por el acto perceptivo. Tales constituyen la manie$\mathrm{ra}$ que siguieron estos autores y otros que ofrecieron variantes. El orden rústico de Serlio llegó, en algunas portadas, a romper la estructura arquitectónica para unificarla, mediante la fusión de elementos, con la masa del edificio. Lo sensitivo tiene un doble juego ilusorio: visual y táctil ${ }^{33}$. Tal es próximo a las chimeneas y portadas antro-

\footnotetext{
${ }^{32}$ Me refiero a la difusión de fórmulas convencionales de fácil aplicación.

${ }^{33}$ Pues los sillares del paramento se prolongan a los dados de los fustes de las columnas que, de modo alternativo, presentan las superficies pulidas y sin desbastar.
} 
pomorfas, como las de Alessandro Vittoria, en el Palacio Thiene, en 1552-53, y Federico Zuccaro, en el jardín de su Palacio, en 1593, en Roma. También podemos hablar aquí de la fusión de la materia y la naturaleza en las esculturas colosales de Giambologna, en 1575; y, por supuesto, de la integración del jardín con los géneros plásticos y del caso concreto de las grutas.

Queda por comentar la decoración como proyecto $^{34}$. En todo el Renacimiento Tardío hubo una clara tendencia a destacar el género que se practicaba sobre los demás. La decoración, planteada en sí, primó sobre los géneros de los que se sirvió y con los que no tuvo obligaciones. En cuanto maniera, no se trató de una multiplicación indiscriminada de elementos, pues, apoyada en la difusión de los tratados, siguió complejos programas. Ellos tuvieron fundamentos diversos, ya alegóricos, ya religiosos, ya propagandísticos, ya moralizantes; y todos revirtieron en la ontología virtuosista y el estímulo sensorial. El aparato decorativo de Vasari relegó a la pintura en el Studiolo de Francisco I. Con Rosso y Primaticcio, la escultura se convirtió en decoración misma, que renunció a sus valores prístinos y, a la vez, enmarcó y ocultó a la pintura, o casi, en las salas de Fointenebleau. Incluso los elementos arquitectónicos de Oviedo, El Joven, en la bóveda de la escalera del Convento de la Merced, en Sevilla ${ }^{35}$, no son tales, sino labores decorativas en estuco. La maniera decorativa, en la que confluyeron conceptos expuestos, se distinguió, en su conceptualismo, de los casos que, sin plantear lo decorativo como tal, y perdida la armonía renacentista, se opusieron a la Gesamtkunswerk con la indisimulada preponderacia de un género sobre otro. En nuestro caso, la erudición procuró ambientes refinados en extremo y el componente fantástico del manierismo tornó en auténtico capricho.
${ }^{34}$ Esto es, como fundamento y medio expresivo que se ha de valorar en conjunto y sobre las artes aplicadas que utilizó
${ }^{35}$ V. PÉREZ EsColAno, Juan de Oviedo y de la Bandera, Excma. Diputación Provincial, 1977, pág. 59. 


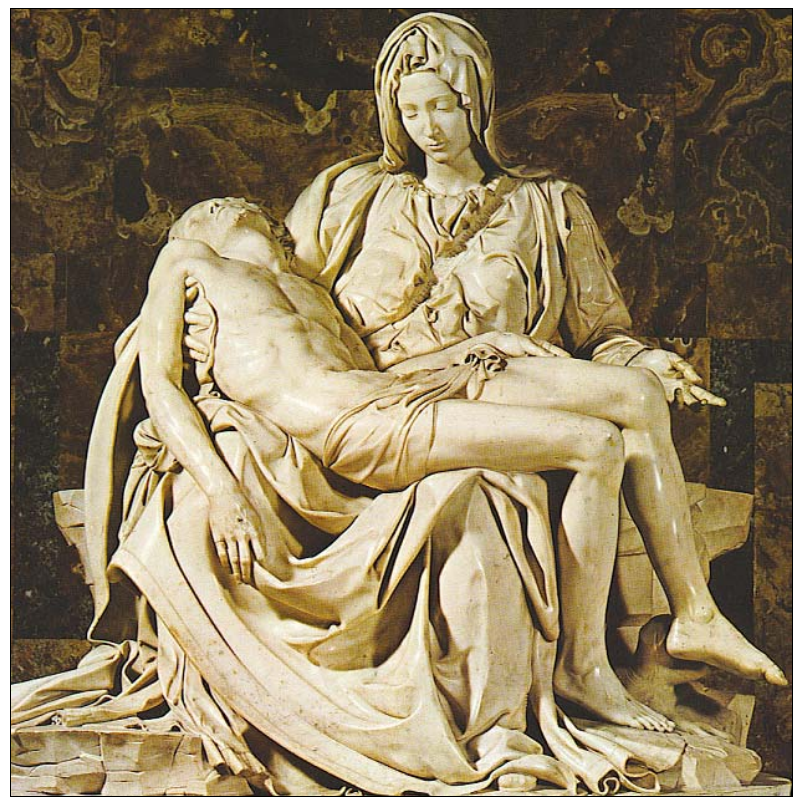

- Fig. 1. Miguel Ángel, Piedad, 1497. Basílica de San Pedro, Vaticano. U. BALDINI 14. La evolución hacia la Maniera de Miguel Ángel se puede seguir a través de sus esculturas de la Piedad. En la del Vaticano siguió los esquemas armónicos de módulos geométricos procedentes del clasicismo pleno.

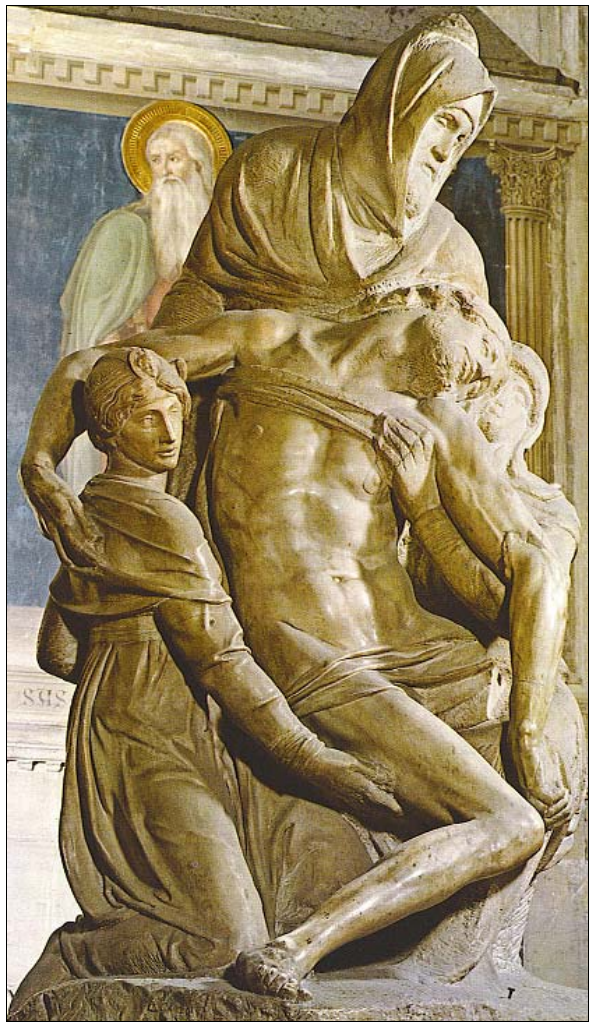

- Fig. 2. Miguel Ángel, Piedad, 1550-55. Duomo de Florencia. U. BALDINI 49. La línea serpentinata requiere el protagonismo visual, pero está supeditada a la pirámide visual. 


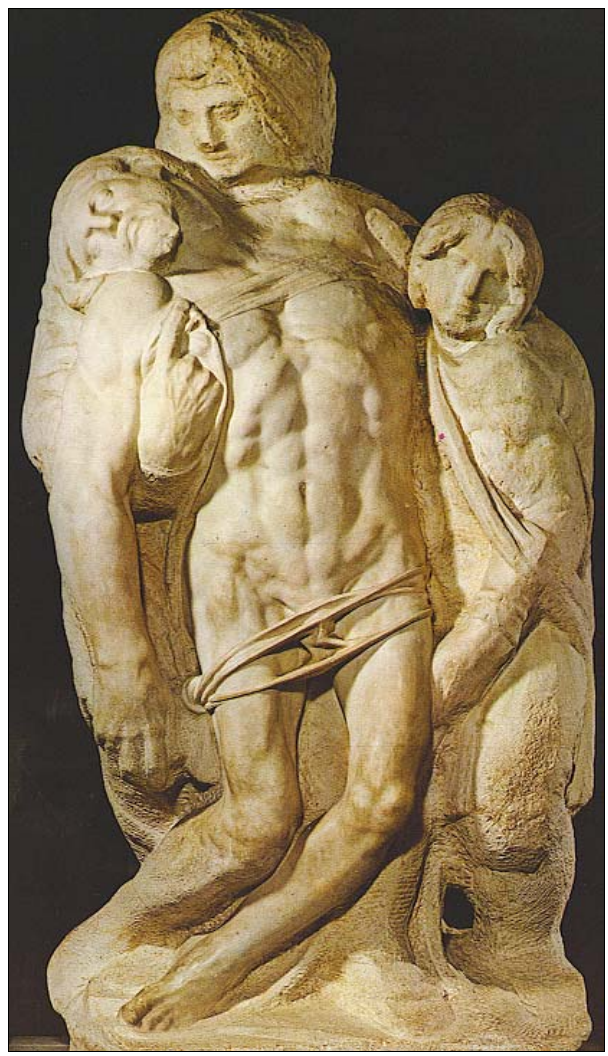

- Fig. 3. Miguel Ángel, Piedad de Palestrina, c. 1555. Galería de la Academia, Florencia. U. BALDINI 50. El impulso ascencional de la línea serpentinata se proyecta con libertad, sin inscripciones en figuras geométricas rectoras

- Fig. 4. Miguel Ángel, Piedad Rondanini, 1552-1564. Museo del Castillo Sforza.U. BALDINI 52. La libertad técnica y expresiva es plena. la Maniera de Miguel Ángel no tiene parangón posible.

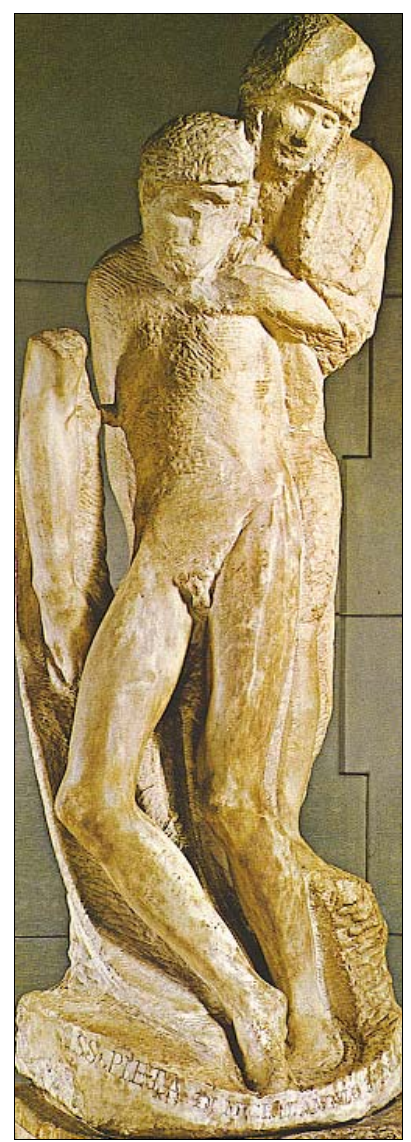




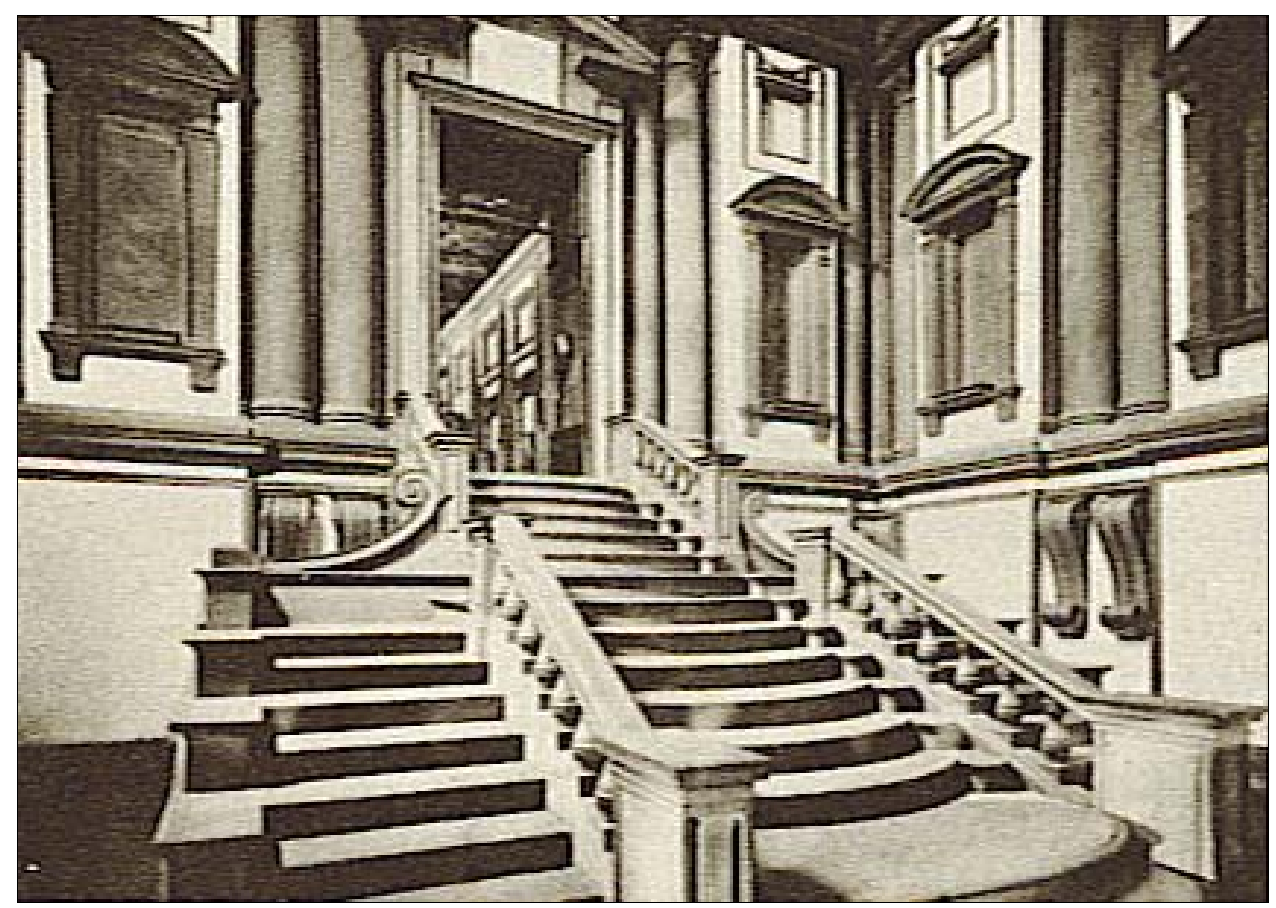

- Fig. 5. Miguel Ángel, Escalera de la Biblioteca Laurenziana, 1523-71. E. CAMESASCA 111. La inscripción de la escalera en la estancia previa, cuyo espacio ocupa de modo masivo, es indicativa de la libertad compositiva de su autor.

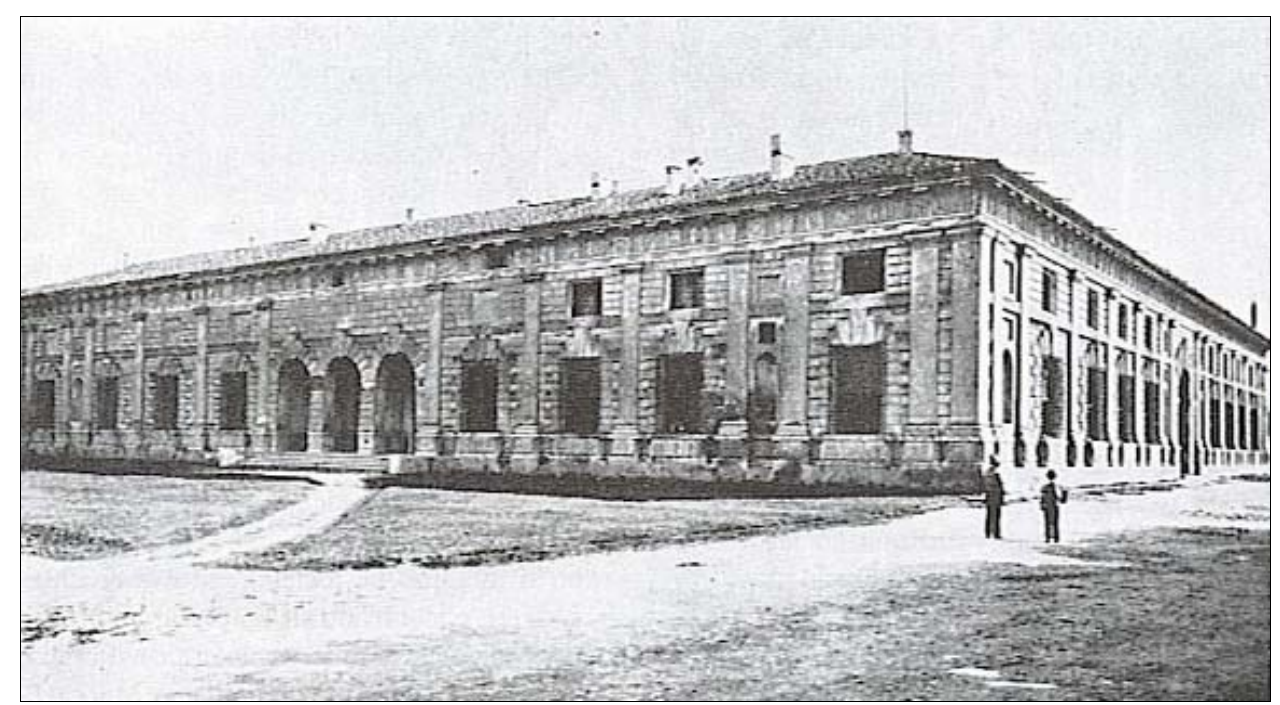

- Fig. 6. Giulio Romano, Palacio del Té, Mantua. HEYDENREICH 230. Es uno de los máximos exponentes de Maniera personal en arquitectura. Los distintos diseños de las fachadas alteran los posibles regímenes de equivalencia, y las combinaciones de elementos sustentantes rústicos y bóvedas de refinada traza generan tensiones irracionales, debidas a la subjetividad propia. 


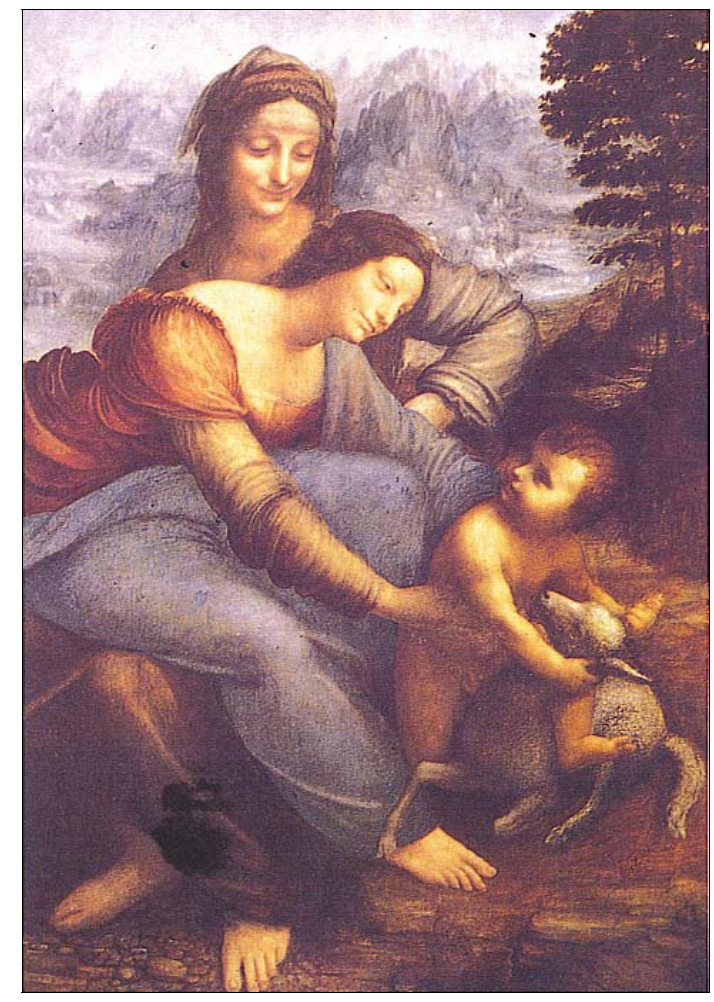

- Fig. 8. El Greco, La visitación, 1607-14. Algunos artistas mantuvieron el significado inicial de la Maniera, como El Greco, que, aunque se atuvo a las codificaciones derivadas de Cesariano y Parmiginiano, no fue un amanerado codificado, se expresó con extraordinaria personalidad en la aplicación del color.
- Fig. 7. Leonardo da Vinci, Sagrada Familia, 1506. Museo del Louvre, París. La captación de la atmósfera mediante las tonalidades azules y la pérdida de visibilidad de los contornos caracterizan la propuesta creativa de Leonardo. Los estudios personales de los mecanismos de la visión generaron una Maniera única.

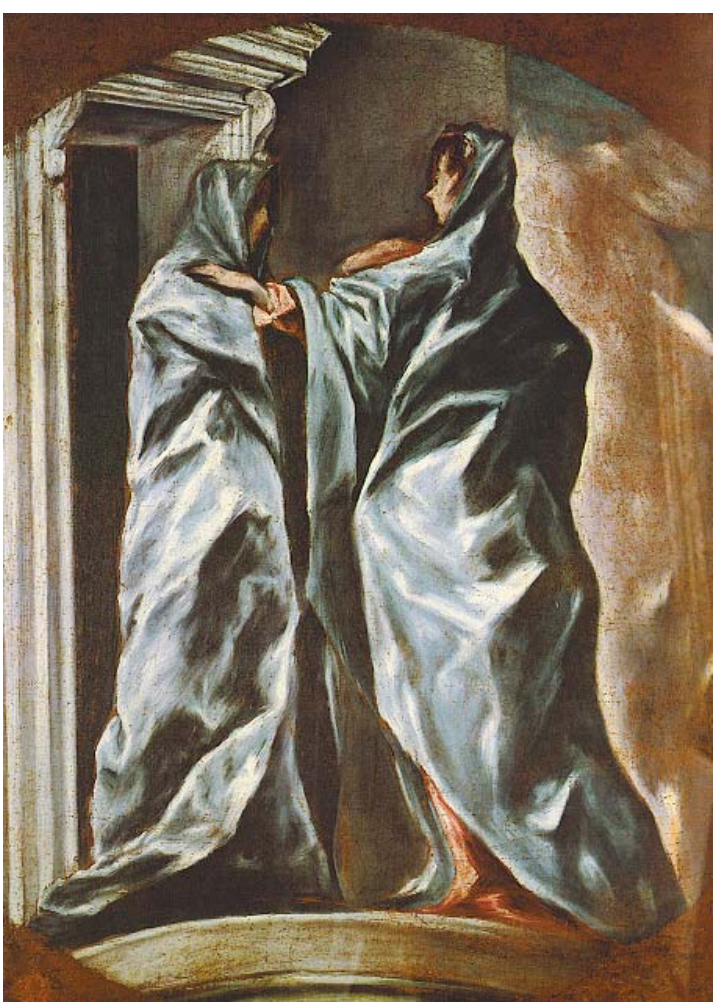

